\title{
PARP-1 cleavage fragments: signatures of cell-death proteases in neurodegeneration
}

\author{
Ganta Vijay Chaitanya ${ }^{1,2}$, Jonathan S Alexander ${ }^{2}$, Phanithi Prakash Babu ${ }^{1 *}$
}

\begin{abstract}
The normal function of poly (ADP-ribose) polymerase-1 (PARP-1) is the routine repair of DNA damage by adding poly (ADP ribose) polymers in response to a variety of cellular stresses. Recently, it has become widely appreciated that PARP-1 also participates in diverse physiological and pathological functions from cell survival to several forms of cell death and has been implicated in gene transcription, immune responses, inflammation, learning, memory, synaptic functions, angiogenesis and aging. In the CNS, PARP inhibition attenuates injury in pathologies like cerebral ischemia, trauma and excitotoxicity demonstrating a central role of PARP-1 in these pathologies. PARP-1 is also a preferred substrate for several 'suicidal' proteases and the proteolytic action of suicidal proteases (caspases, calpains, cathepsins, granzymes and matrix metalloproteinases (MMPs)) on PARP-1 produces several specific proteolytic cleavage fragments with different molecular weights. These PARP-1 signature fragments are recognized biomarkers for specific patterns of protease activity in unique cell death programs. This review focuses on specific suicidal proteases active towards PARP-1 to generate signature PARP-1 fragments that can identify key proteases and particular forms of cell death involved in pathophysiology. The roles played by some of the PARP-1 fragments and their associated binding partners in the control of different forms of cell death are also discussed.
\end{abstract}

\section{Introduction}

PARP-1 is a nuclear protein with a wide range of physiological as well as pathological functions. Initially identified as an enzyme that performs central roles in the repair of damaged DNA, PARP-1 participates in initiating base excision repair (BER) (PARP-1 ${ }^{-1-}$ cells have impaired BER activity) [1,2], nucleotide excision repair, single strand base repair mediated by DNA ligase III, XRCC1, poly nucleotide kinase, proliferating cell nuclear antigen and flap endonuclease-1, and contributes to double strand base (DSB) repair in an alternate nonhomologous end joining pathway with DNA ligase III [3-6]. Interestingly, over-expression of PARP-1 or DNA binding domain of PARP-1 (lacking catalytic domain) decreased DSB repair, indicating that its enzymatic activity is not essential in all repair processes [7]. Many additional functions of PARP-1 have now been demonstrated in biochemical and molecular signaling [8]. Apart from its role in repairing DNA damage, PARP-1 also plays important roles in transcription, cardiac

\footnotetext{
* Correspondence: ppbsl@uohyd.ernet.in

'Department of Biotechnology, School of Life Sciences, University of Hyderabad, Hyderabad, India

Full list of author information is available at the end of the article
}

remodeling, vasoconstriction, regulation of astrocyte and microglial function, long term memory and aging [9-17]. Progressive DNA damage and decreased PARP-1 activity in aging neurons eventually leads to programmed neuronal death and loss of memory consolidation. PARP-1's role in neuronal BER indicates that it may influence age-related memory deficits and dementia. Further, over-expression of PARP-1 and telomeric repeat binding factor-1 were also associated with age dependent telomere shortening in 'Duchenne muscular dystrophy' [18]. PARP-1 influences $\sim 3.5 \%$ of the total transcriptome of embryonic liver and stem cells and regulates $\sim 60-70 \%$ of genes controlling cell metabolism, cell cycle and transcription. Gene expression is dysregulated in PARP-1 deficient fibroblasts and PARP-1 deficient mice are more susceptible to skin diseases [19-21] reflecting the role of PARP-1 against UV-induced DNA damage. PARP-1 also interacts with, and modulates the function of several transcription factors including NF- $\kappa \mathrm{B}, \mathrm{NFAT}, \mathrm{E} 2 \mathrm{~F}-1$, and ELK-1 [22-28]. PARP-1 is also involved in modulating endothelial cell adhesion molecule expression (e.g. during atherogenesis) via its binding partner NF- $\kappa \mathrm{B}[16,29,30]$. PARP-1, 2 and 3 can activate CNS immune responses by promoting astrocyte production of inflammatory 
cytokines like TNF- $\alpha$, IL-1 $\beta$, nitric oxide and the chemokine CCL2 after challenge with Staphylococcus aureus, a common CNS infectious agent [14].

The PARP family consists of 17 members which have different structures and diverse functions in cells [31]. PARP-1, the canonical representative of this superfamily has become the major focus of research due to its multifaceted roles in many cellular activities. This review focuses on the interactions between PARP-1 and suicidal proteases like caspase, calpain, granzyme, and MMPs that lead to the formation of PARP-1 proteolytic signature fragments associated with particular pathological conditions.

PARP-1 is an abundant nuclear enzyme with approximately 1-2 million copies in the cell which account for $\sim 85 \%$ of total cellular PARP activity [31-34]. Posttranslation modification involving poly (ADP-ribosyl) ation plays a central role in cellular homeostasis [35]. Protein modifications involving phosphorylation, acetylation, methylation and poly (ADP ribosyl)ation are vital cellular processes that are required for cell signaling, survival and functioning [34,36-39]. This form of post translational modification is mainly mediated by PARP1 which catalyzes the formation of chains approximately 200 units long linear or branched poly (ADP ribose) units from donor $\mathrm{NAD}^{+}$molecules frequently linked by esterification to glutamate, and less commonly to aspartate or lysine resides on target molecules [34,40]. Poly (ADP-ribosyl)ation is therefore an important mechanism for maintaining genome integrity, replication, transcription, protein degradation, differentiation and in the repair process following DNA damage [13,34,41-43].

PARP-1 has several important domains: a 54-kD catalytic domain (CD) at the carboxyl terminus that polymerizes linear or branched poly-ADP ribose units (from $\mathrm{NAD}^{+}$) on target proteins, a 46-kD DNA binding domain (DBD) containing 2 zinc finger motifs (at the $\mathrm{NH}_{2}$ terminus), and 22-kD auto-modification domain (AMD) that functions as a target for direct covalent auto-modification in its central region [34]. For example, high affinity binding of PARP-1 to specific DNA motifs like double-strand breaks, cruciforms, cross-overs and nucleosomes require the DBD for active modification [44-46]. While the 2 zinc finger motifs at the N-terminus facilitate tight binding of PARP-1 to DNA and promotes the activation of the catalytic domain at the C-terminus, a $3^{\text {rd }}$ zinc finger motif located between $2^{\text {nd }}$ zinc finger motif and AMD also plays an important role in the inter-domain interactions and is vital for PARP-1 enzymatic action [47]. AMD contains a BRCT fold (a motif also found in many DNA repair proteins) that is involved in protein-protein interactions which promotes the recruitment of DNA repair enzymes to the site of DNA damage $[48,49]$. These PARP-1 domains play different roles in various pathological cell death processes mediated by PARP-1 cleavage by suicide proteases. These suicidal proteases (caspases, calpains, cathepsins, granzymes and MMPs) cleave PARP-1, creating PARP-1 fragments with diverse, exposed structural domains mediating specific forms of cell death. The present review focuses on the different actions of these proteases towards PARP-1, the production of a variety of different PARP-1 signature fragments, and the specific patterns of cell death linked with particular PARP-1 fragments.

\section{PARP-1 and Caspases}

Apoptosis, the process of programmed cell death is essential for proper homeostatic maintenance and survival in multi-cellular organisms. Physiological apoptosis controls cell numbers, tissue and organ morphology and patterning, and removes injured or mutated cells $[50,51]$. Dysregulated apoptosis results in elevated or decreased cell death often leading to neurodegenerative disorders, cancer and other hyper-proliferative disorders $[52,53]$. One of the most common signaling cascades involved in apoptosis is the activation of a highly specialized family of cysteinyl-aspartate proteases (caspases) which are usually present as inactive zymogen forms. Once activated, caspases initiate cell death by cleaving and activating effector caspases which drive the process of apoptosis [54]. Interestingly, recent reports have shown the involvement of caspases not only in apoptosis, but also in forms of cell proliferation in a Drosophila model. One of the 2 distinct forms of 'apoptosis induced compensatory proliferation' (AICP) depends on initiator caspase Dronc (initiator caspase in Drosophila, caspase9-like); the other is dependent on execution caspase DrICE and Dcp-1 (effector caspases in Drosophila; caspase-3-like) [55-58]. Moreover, apart from their primary function in executing apoptosis, non-apoptotic functions of caspases include hematopoiesis (erythropoiesis, monocyte, lymphocyte differentiation, platelet maturation) [59] and regulation of neuronal synaptic plasticity in long-term potentiation $[60,61]$. Caspase mediated apoptotic cell death is accomplished through the cleavage of several key proteins required for cellular functioning and survival [62]. PARP-1 is one of several known cellular substrates of caspases. Cleavage of PARP-1 by caspases is considered to be a hallmark of apoptosis [63,64]. Almost all caspases including caspase1 , are known to modify PARP-1 in vitro [65]. Lazenbik et al., have observed protease activity resembling interleukin converting enzyme (prICE: caspase-3) which cleaves PARP-1 after aspartate (glutamate-valine-aspartate-glycine), a substrate specificity identical to one of ICE cleavage sites in vitro to yield an $85-\mathrm{kD}$ PARP-1 fragment [66]. Cleavage of PARP-1 by caspase- 3 has been implicated in several neurological diseases e.g. 
cerebral ischemia, Alzheimer's disease, multiple sclerosis, Parkinson's disease, traumatic brain injury, NMDAmediated excitotoxicity and brain tumors, especially gliomas [67-74]. Besides caspase-3, caspase-7 also cleaves PARP-1 in vivo. The cleavage of PARP-1 by these caspases results in the formation of 2 specific fragments: an $89-\mathrm{kD}$ catalytic fragment and a $24-\mathrm{kD}$ DBD $[65,66]$. The $89-\mathrm{kD}$ fragment containing AMD and the catalytic domain of the enzyme has a greatly reduced DNA binding capacity and is liberated from the nucleus into the cytosol [75]. The 24-kD cleaved fragment with 2 zinc-finger motifs is retained in the nucleus, irreversibly binding to nicked DNA where it acts as a transdominant inhibitor of active PARP-1. Importantly, irreversible binding of the 24-kD PARP-1 fragment to DNA strand breaks inhibits DNA repair enzymes (including PARP-1) and attenuates DNA repair (also conserving cellular ATP pools) [76-78]. Poly (ADP-ribosyl)ation of PARP-1 following DNA breaks changes PARP-1 targeting from caspase- 3 from caspase-7 in human promyelocytic leukemia cells (HL-60) treated with etoposide phosphate (VP-16). However, increased caspase-3 levels (and activity) might lead to PARP-1 cleavage irrespective of its auto-modification (by poly (ADP-ribosyl)ation) [79]. In a similar context, Margolin et al., using the 46-kD DBD of PARP-1 (lack which auto-modification sites) reported an increased affinity of caspase-3 for PARP-1, indicating a prominent role for PARP-1 automodification sites in caspase-3 mediated proteolytic cleavage [65].

Under basal conditions, the primary function of PARP-1 is to detect and repair DNA damage. However, cells with severely damaged DNA have amplified PARP1 activity resulting in high $\mathrm{NAD}^{+}$consumption (depleting ATP pools). If unchecked, this activity inevitably leads to passive necrotic cell death (resulting from prolonged ATP depletion) $[80,81]$. This process is blocked by rapid cleavage and inactivation of PARP- 1 by the action of caspases $[81,82]$. However, insults which initiate necrosis cause PARP-1 overactivation that proceeds unchecked due to inadequate caspase activation [82-84], lower PARP-1 cleavage and less PARP-1 24-kD fragment formation. It is therefore possible that exogenous addition of PARP-1 24-kD fragments could attenuate PARP-1 overactivation possibly blocking cell death. Exogenous administration of 24-kD PARP-1 fragments might attenuate PARP-1 overactivation and divert necrosis towards apoptotic cell death. Taken together, these findings suggest that the PARP-1 24-kD fragment can also serve as a powerful therapy for CNS disorders like cerebral ischemia where necrotic cell death predominates within the infarct core. PARP-1 cleavage by caspases and the resulting specific fragmentation patterns are indicated in figure 1 and Additional file 1: Table-1.

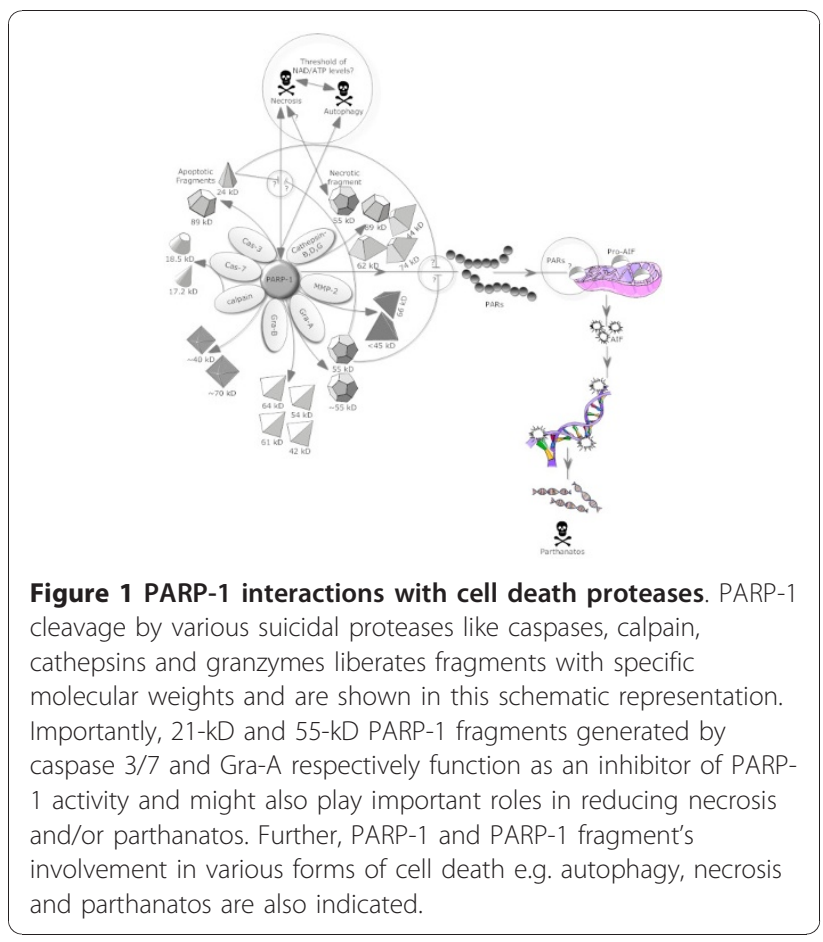

\section{PARP-1 and Calpains}

Calpains are a family of $14 \mathrm{Ca}^{2+}$-activated, non-lysosomal cysteinyl proteases active at neutral $\mathrm{pH}$ [85]. Of all the calpain isoforms, $\mathrm{m}$-calpain and $\mu$-calpain (activated at $\mu \mathrm{M}$ $\mathrm{mM} \mathrm{Ca}{ }^{2+}$ concentrations) are the best understood. Alterations in intracellular calcium levels are known to initiate calpain activation often exacerbating pathological conditions [86]. For example, pathologic calpain activation aggravates neurodegenerative disorders like cerebral ischemia, neonatal hypoxia, cerebral malaria, Alzheimer's disease, Parkinson's disease, Huntington's disease, multiple sclerosis, and also contributes to injury in brain tumors, such as gliomas [68-70,87-92]. Translocation of calpains to the plasma membrane is required for optimal calpain activation. However in neurons, NMDA-mediated excitotoxicity involves calpain activation without a requirement for membrane translocation $[93,94]$. Calpains also play prominent roles in normal physiology e.g. neuron synaptic signaling, myoblast differentiation, cell migration, embryonic development (where m-calpain deficiency is embryonic lethal) and angiogenesis [95-98]. VEGF mediated angiogenesis involves increased $\mathrm{Ca}^{2+}$ uptake in cells to activate $\mathrm{m}$-calpain and VEGF induced retinal angiogenesis in vitro could be reversed by the calpain inhibitor SNJ-1945 $[99,100]$. Interestingly, PARP-1 inhibition also been shown to decrease VEGF induced angiogenesis [101]. Hence, even though calpain mediated PARP-1 proteolysis can decrease angiogenesis; calpains might still promote angiogenesis by augmenting VEGF expression [100] indicating 
that a bimodal activation pattern of calpain activation proportional to the magnitude of calpain mediated PARP-1 proteolysis is possible. More studies are still required to address this issue and understanding the roles played by PARP-1, calpains and VEGFs in post-ischemic cerebral angiogenesis is an area of drug development, particularly for stroke therapy.

Calcium, apart from activating calpains, also promotes PARP-1 hyper-activation through production of ROS and peroxynitrite [102]. The anti-tumor drug $\beta$-lapachone induces PARP-1 dependent cell death independent of caspases via metabolic starvation. $\beta$-lapachone treated cells also exhibit increased cytosolic $\mathrm{Ca}^{2+}$ (by release of endoplasmic reticulum $\mathrm{Ca}^{2+}$ stores) and ROS, resulting in PARP-1 hyper-activation. PARP-1 hyperactivation by $\beta$-lapachone was blocked by BAPTA-AM (a cytosolic $\mathrm{Ca}^{2+}$ chelator) indicating that $\mathrm{Ca}^{2+}$ induced ROS generation leads to PARP-1 hyper-activation and cell death [103]. Conversely, cellular $\mathrm{Ca}^{2+}$ levels were altered by PARP-1 in doxorubicin-induced myocardial injury. Szenczi et al., have shown that both cardiac contractile capacity and intracellular $\mathrm{Ca}^{2+}$ loading was reduced in doxorubicin-treated hearts, an effect blocked by PARP-1 inhibition. These responses may be indirect through the effects of PARP-1 on the transcription of proteins involved in $\mathrm{Ca}^{2+}$ handling and $\mathrm{Ca}^{2+}$ pumps [104]. PARP-1 has also been shown to modulate neuronal mitochondrial $\mathrm{Ca}^{2+}$ levels [105]. PARP-1 activity raises intra-mitochondrial $\mathrm{Ca}^{2+}$ levels, activating $\mu$-calpain to release mitochondrial apoptosis inducing factor (AIF) [106]. However, because activated calpains mediate proteolytic breakdown of PARP-1, the temporal association of PARP-1 and calpain in AIF nuclear translocation may be phase-dependent, more studies will be required to address this. The roles of PARP-1 in $\mathrm{Ca}^{2+}$ handling and excitotoxicity point towards pleiotropic functions of PARP-1 in pathological settings.

Calpains play crucial roles in both caspase-dependent and independent forms of apoptotic cell death and are key mediators of necrotic cell death $[107,108]$. A variety of cellular insults can activate calpains including increased cytosolic $\mathrm{Ca}^{2+}$, decreased calpastatin levels, interactions with calpain activator protein, phospholipids, and caspase activation [109-112]. Several cell substrates have been identified as calpain targets resulting in proteolytic breakdown to signature fragments of specific molecular weights $[69,91,113]$. Appearance of distinctive cleavage ('signature') fragments is considered to represent specific forms of calpain activation. Among the various cellular substrates of calpain, PARP-1 cleavage gives rise to a $40-\mathrm{kD} \mathrm{N}$-terminal fragment in neuroblastoma cells (SH-5YSY) challenged with maitotoxin [114]. $\mu$-calpain isolated from calf thymus generates 40-70-kD N-terminal PARP-1 fragments [115]. Calpain induced $40-\mathrm{kD}$ fragments were recognized by both $\mathrm{C}-2$ 10 and N-20 antibodies (which detect PARP-1 fragments bearing the $\mathrm{N}$-terminal domain/DBD). Depending on observed molecular weight and immunoreactivity it can be presumed that this PARP-1 fragment might have DBD domain, but not AMD or catalytic domains. Whether this $40-\mathrm{kD}$ fragment plays any role in PARP-1 auto-modification (as shown in studies on the 24-kD PARP-1 DBD fragment) is not yet known. This fragment appears specifically when PARP-1 is digested with calpain, and $\mu$-calpain inhibitor reduces its appearance, indicating that it is a $\mu$-calpain-specific PARP-1 signature fragment. We don't know whether this fragment represents a byproduct formed during calpain mediated necrotic cell death or if it can actively attenuate necrosis. Based on the findings that the zinc finger motifs present in the DBD domain of PARP-1 can facilitate irreversible binding of DBD to DNA nicks and promote transdominant inhibition of activated PARP-1, the appearance of this fragment would be consistent with its ability to attenuate PARP-1 activity during calpain mediated necrosis. Calpains are known to mediate apoptotic cell death. Whether this fragment appears only during necrotic conditions or also during calpainmediated (caspase independent) apoptosis is unknown. Future studies on the molecular biology of this fragment and its roles in specific cell death pathways will be needed to determine its role in neuronal pathologies. So far, these fragments remain most convincingly related to necrotic modes of cell death mediated by calpain.

Apart from PARP-1, caspase-7 has also been shown to be a target of $\mu$-calpain. $\mu$-calpain cleaves caspase- 7 to active 18.5 and $17.2-\mathrm{kD}$ fragments. This calpain generated caspase-7's 17.2-kD fragment is $\sim 18$ fold more active than the $20-\mathrm{kD}$ caspase-3 generated fragment of caspase-7 [116]. Whether these fragments are involved in preferential PARP-1 processing over caspase- 3 is not yet known. PARP-1 cleavage by calpains results in specific fragmentation patterns which are described in figure 1 and Additional file 1: Table-1.

\section{PARP-1 and Cathepsins}

Lysosomes were initially described as participants in catabolic autophagic cell death when exhausted or damaged organelles were digested and secreted into the cytoplasm [117]. Lysosomes and lysosomal proteases also participate in apoptotic and necrotic forms of cell death [118-120]. Cathepsins belong to the family of lysosomal proteases which are active at acidic $\mathrm{pH}$. These are stored in lysosomes as inactive precursors and activated by stimuli that lower cell $\mathrm{pH}$, resulting in the release of their catalytically active forms which cleave multiple targets [121]. Cathepsins can initiate apoptotic cell death independent of caspases, and are known to be key 
proteases in necrosis and autophagy. Increased autophagic protease levels can aggravate post-ischemic neuropathologic with injury [122]. Recent reports clearly show that the biogenesis of lysosomal cathepsins is required for necrotic cell death [118]. One of the important differences between apoptotic and necrotic forms of cell death is the protein synthesis pattern. During apoptotic cell death, normal protein synthetic processes are rapidly shut down, an event which conserves ATP, which is used to accomplish apoptosis. Conversely, the persistence of protein synthesis during necrotic cell death can deplete energy reserves accelerating necrotic cell death [118-123]. Since lysosomal biogenesis is required for necrotic cell death, persistent protein synthesis might help in lysosomal-cathepsin synthesis, which eventually spills into the cytosol, cleaving PARP-1 and contributing to cell death $[118,123]$. However, the numerous targets and temporal specificities of cathepsins and PARP-1 contributing to cell death mechanisms require further study.

Cathepsins are a large family of lysosomal enzymes comprising 11 cysteinyl cathepsins (and aspartyl protease cathepsin-D) which are also active at neutral $\mathrm{pH}$. These have a relatively short biological half-life, but acidification of the cytosol will increase their residence time. However, due to the abundance of cathepsin B, D and $\mathrm{L}$, these are most often used as markers for the involvement of lysosomes in particular forms of cell death [119]. Cathepsins B, S and G are also involved in tumor invasion (glioblastoma multiforme, breast cancer bone metastasis and colorectal tumors), endothelial proliferation and in angiogenesis (via TGF- $\beta$, VEGF and MCP-1) [124,125]. It is important to note that necrosis is common in tumor tissue and is usually accompanied by PARP-1 hyper activation. Considering that PARP-1 inhibition reduces angiogenesis, it is possible that hyperactivated PARP-1 might in part drive tumor angiogenesis and metastasis. Cathepsins and TGF- $\beta$ are also involved in caspase-independent PARP-1 cleavage (an $\sim 85-\mathrm{kD}$ caspase independent PARP-1 fragment is produced by TGF- $\beta$ ) [126]. How these mediators drive angiogenesis or can be used in diagnosis or therapy needs further study.

Moreover, TGF- $\beta$ and cathepsin-G mediated angiogenesis depends on the upregulation of VEGF [124]. Hence, breakdown of PARP-1 (which would reduce the angiogenic program) might be balanced by increased VEGF production by cathepsins. It is important to identify whether the breakdown products of PARP-1 produced by calpains or cathepsins can substitute for the PARP-1 function in angiogenic programs. More importantly, the effect of transdominant inhibition of PARP-1 by $\mathrm{DBD}$ in modulating angiogenic programs is worth investigating. These findings indicate that angiogenesis associated with PARP-1 signaling is highly complex, tightly controlled and pathology specific. The extent of PARP-1 and PARP-1 cleavage products' involvement in modulating angiogenic programs has yet to be fully determined.

Cysteine cathepsins also share several common targets along with PARP-1. PARP-1 was initially found to produce a $50-\mathrm{kD}$ fragment (necrotic fragment) during necrotic cell death. Necrotic PARP-1 fragmentation was later characterized and the appearance of these PARP-1 fragments shown to be mediated by lysosomes and lysosomal specific proteases cathepsin-B, -D and -G. During necrosis, induced by $\mathrm{H}_{2} \mathrm{O}_{2}, 10 \%$ ethanol, $\mathrm{HgCl}_{2}$, lysosomal extracts and cathepsin-B, PARP-1 gave rise to fragments ranging from 42-89-kD [127]. Cathepsin-B and D produce active PARP-1 fragments with molecular weights of $55-\mathrm{kD}$ and $42-\mathrm{kD}$, similar to the fragments obtained from the lysosomal extracts. Inactive PARP-1 fragments with molecular weights of 74 and $62-\mathrm{kD}$ are also liberated by the action of these proteases. Cathepsin-G, another lysosomal protease, also produced a similar fragmentation pattern, but with lower intensity (requiring longer incubation periods vs. cathepsin-B and D). Moreover, the $89-\mathrm{kD}$ PARP-1 fragment which appears during apoptotic cell death could also be produced by cathepsin$B$ and D, but is not generated by cathepsin-G [127]. Cathepsin specific PARP-1 fragmentation patterns are shown in figure 1 and Additional file 1: Table-1.

\section{PARP-1 and granzymes}

The immune system maintains an internal homeostasis by recognizing and reacting to foreign particles, abnormal or infected cells to restrict their further persistence and penetration within the host. Immune processes use highly specialized and cell-specific mechanisms and molecules to accomplish this. Induction of cytotoxicity in target cells is a multifactorial process accomplished by cytotoxic $\mathrm{T}$ lymphocytes (CTLs) and natural killer (NK) cells that secrete toxic and lytic proteases of the serine protease family (granzymes), perforins and granulysin [128]. About 90\% of cytolytic granules stored in CTLs and NK cells contain granzymes. Granzymes are subdivided into 3 categories based upon their enzymatic similarity to chymotrypsin (chymase locus), trypsin (tryptase locus) and those that cleave after unbranched hydrophilic residues particularly after methionine (Metase-locus). A total of 10 granzymes have been found in the mouse (granzymes $A-G$ and $K-M), 7$ in rats $(A, B$, $\mathrm{C}, \mathrm{I}, \mathrm{J}, \mathrm{K}$ and $\mathrm{M}$ ) and 5 in humans (granzymes $\mathrm{A}, \mathrm{B}, \mathrm{H}$ which are specific to human, $M$ and tryptase $2 /$ granzyme-3). Human homologs of granzymes C-G have still not been found [129].

Granzymes are secreted from cytotoxic cells upon recognizing their target cells, with several physiological 
or pathophysiological consequences. Physiologically, granzymes promote extracellular matrix degradation, lymphocyte migration, cytokine production and attenuate tumor cell migration[130]. Pathological granzyme actions are important in inflammatory vascular disorders (atherosclerosis, transplant vascular disease, systemic lupus erythrematosus, autoimmune vasculitis) [131-133], chronic allergic or autoimmune diseases (arthritis, chronic allergic asthma, hypersensitive pneumonitis) [134-136] and neurodegenerative disorders (spinal cord injury, cerebral ischemia, multiple sclerosis, brain tumors like gliomas) $[68,70,137-139]$. Of the family of granzymes, granzyme-B (Gra-B) is considered to be the most potent apoptogenic molecule, even though granzyme-A (Gra-A) and Gra-B are the most abundant proteases in lytic granules [140]. Other members of the granzyme family perform functions outside of apoptosis and independent of caspases.

Gra-A has been shown to induce caspase-independent, but morphologically indistinguishable apoptosis. Induction of Gra-A mediated apoptosis involves activation of Gra-A activated DNase to induce single stranded nicks in DNA, breakdown of oxidative repair protein 'apurinic/apyrimidinic (AP) endonuclease' (APE), KU-70 and mitochondrial complex I protein [141-144]. Apart from lamin, which is the common substrate for Gra-A, Gra-B and caspase-3, PARP-1 is also cleaved by these 3 proteases resulting in different fragmentation patterns [66,145-147]. Importantly, even though PARP-1 is a direct substrate for Gra-A it can only cleave intracellular PARP-1 in the presence of perforins [145]. This finding also underscores the necessity of perforin for Gra-A to enter the cell to execute cell death, unlike Gra-B. Gra-A activity towards PARP-1 results in its breakdown with high efficiency after Lys ${ }^{498}$ leading to the formation of a $\mathrm{C}$-terminal 55-kD inactive fragment and an $\mathrm{N}$-terminal fragment of similar molecular weight. Cleavage of PARP-1 at Lys ${ }^{498}$ residue by Gra-A results in decreased auto-modification of PARP-1, poly (ADP ribosyl)ation and DNA repair. Gra-A mediated formation of N-terminal active 55-kD PARP-1 (after Lys ${ }^{498}$ ) may cause cells to undergo caspase-independent apoptotic cell death, rather than necrotic cell death, by decreasing the efficiency of ADP ribosylation. Since Gra-A cleaves oxidative repair enzymes and increases ROS production, it will indirectly activate PARP-1; decreased poly (ADPribosyl)ation counteracts these deleterious effects [145]. However, whether Gra-A has any role in 'parthanatos' (cell death mediated by poly (ADP ribose) polymers) or necrosis is a topic for future studies. Even though cathepsin-B and Gra-A produce similar 55-kD C-terminal PARP-1 fragments, they differ in recognized cleavage sites. For example, cathepsins cleave PARP-1 at leucine $^{525}$ residues, but Gra-A cleaves preferentially at lysine ${ }^{498}[127,145]$ resulting in the formation of N-terminal fragments that attenuate PARP-1 depletion of ATP. Unlike Gra-A, cathepsin mediated PARP-1 cleavage at $\mathrm{Leu}^{525}$ results in the formation of $55-\mathrm{kD}$ active C-terminal and 62-kD inactive $\mathrm{N}$-terminal fragments [127]. Consequently cleavage-site specificity plays a major role in the generation of fragments derived from particular domains that differentially modulate forms of cell death (apoptosis vs. necrosis).

Gra-B was the first serine protease discovered to cleave PARP-1 during induction of cell death. Gra-B can translocate into cells in both a perforin-dependent and independent manner. Unlike Gra-A, Gra-B shares similar substrate specificity with caspase-3 (i.e. it cleaves after aspartate residues) and induces more rapid cell death [140]. Further, Gra-B can mediate apoptosis independent of caspases, or by directly activating caspases or indirectly by activating Bid $[148,149]$.

Apart from various other cellular substrates, Gra-B cleaves PARP-1 into 64-kD and 61-kD N-terminal fragments and C-terminal 54-kD and 42-kD fragments. Of these, the 54-kD and 42-kD PARP-1 fragments were found to be catalytically active, while the $64-\mathrm{kD}$ and 61 $\mathrm{kD}$ fragments were inactive. This was mainly based on the presence of intact catalytic domain at the C-terminus [147]. Using activity western blots, it has been shown that the fragments $54-\mathrm{kD}$ and $42-\mathrm{kD}$ fragments are catalytically active. The $42-\mathrm{kD}$ fragment was detected in activity western blots but not when immunoblotted with $\mathrm{N}$-terminus specific antibody, indicating that it is $\mathrm{C}$-terminus fragment. $\mathrm{N}$-terminal analysis of the 54- $\mathrm{kD}$ fragment has shown that the cleavage site follows $\mathrm{Asp}^{537}$. It was further suggested that the appearance of $42-\mathrm{kD}$ fragment is due to the secondary cleavage of $54-\mathrm{kD}$ and $61-\mathrm{kD}$ fragment was due to the secondary cleavage of 64-kD fragment [147].

The appearance of PARP-1 fragments with multiple molecular weights clearly distinguishes these proteases from each other, and suggests the participation of specific proteases during different phases and forms of pathology. The presence of some PARP-1 fragments, like the $50-\mathrm{kD}$ and $55-\mathrm{kD}$, which can be formed by either necrotic cathepsins or by Gra-A, need to be carefully interpreted $[127,145]$. The PARP-1 fragments created by granzyme action are indicated in figure 1 and Additional file 1: Table-1. Based on the roles of PARP-1 in angiogenesis, whether Gra-B cleavage of PARP-1 and the resulting PARP-1 fragments have any role in modulating angiogenesis during forms of neurodegeneration is a potential opportunity for therapy.

\section{PARP-1 and matrix metalloproteinases}

MMPs are a family of 28 zinc-dependent endopeptidases that play significant roles in angiogenesis, embryogenesis 
and in several pathological cardiovascular diseases like myocardial ischemia, cerebral ischemia, and atherosclerosis [150-152]. Within this family of MMPs, MMP2 has recently been shown to be capable of cleaving PARP-1. Kwan et al. have reported that MMP-2 along with MMP-9 is present in the nuclear fraction of heart and liver, and is able to cleave PARP-1 in a concentration dependent manner. Cleavage of PARP-1 by MMP-2 produces a $66-\mathrm{kD}$ and a $>48-\mathrm{kD}$ fragment (seen in silver stained gels and western blotting) [153] which differ in their appearance. MMP-2 produced a $66-\mathrm{kD}$ PARP-1 fragment in a concentration-dependent fashion whereas there was no difference in levels of other $>48-\mathrm{kD}$ forms from control conditions observed in silver stained gels. Interestingly western blot analysis did not show any 66kD PARP-1 fragments but showed an increase in $>48-\mathrm{kD}$ fragments in a concentration-dependent fashion. The MMP inhibitors TIMP-2 and doxycycline were able to block PARP-1 degradation to a $66-\mathrm{kD}$ fragment. The reason for the appearance of a prominent $\sim 66-\mathrm{kD}$ fragment in TIMP-2 treated conditions and a faint band of the same molecular weight in doxycycline treated samples is curious. Why this fragment is specifically detected in MMP-2 inhibited samples is also unclear. Though the differences in the appearance of $>48-\mathrm{kD}$ and $66-\mathrm{kD}$ fragments may relate to the PARP-1 antibody used (either Cterminus or $\mathrm{N}$-terminus specific), the reason for the appearance of $\sim 66-\mathrm{kD}$ fragment in samples with inhibited MMP-2 (but not in untreated controls) are unclear.

MMPs actions are modulated by the cytokines and endogenous MMP inhibitors in both pro- and antiangiogenic programs affecting extracellular and basement membrane remodeling [154]. MMP-2 is known to be a key protease involved in neovascularization, and MMP-2 $2^{-/-}$mice show defects in neovascularization. Conversely, MMP-9 may limit collagenase-induced intracerebral hemorrhage $[155,156]$. Moreover, conditioned medium enriched in MMP-2 and 9 (from mouse brain endothelial cells) increases the migration of neural precursor cells to sites of brain injury via ERK ${ }^{1 / 2}$ and PI3/ AKT signaling [157]. However, several CNS pathologies such as cerebral ischemia, multiple sclerosis and Devic's neuromyelitis optica are also associated with increased MMP-2 and-9 levels and MMP-9 inhibition is beneficial against cerebral ischemia [151,158]. Nicolescu et al., have recently reported that PARP-1 inhibitors can also inhibit MMPs [159], indicating that at least part of the protection afforded by PARP-1 inhibitors during stroke might be due to MMP inhibition. PARP-1 inhibition undoubtedly rescues cells from necrotic cell death, but the role(s) played by MMP inhibition in stroke clearly deserve further study.

Although acute PARP-1 and MMP inhibition may effectively attenuate ischemic stroke, the roles of MMPs in neuronal progenitor migration, and PARP-1's role in angiogenesis programs during restitution need some clarification. Importantly, whether $66-\mathrm{kD}$ and $>48-\mathrm{kD}$ PARP-1 fragments produced by MMP proteolysis have activity or modulate PARP-1 activity is still unknown. Because PARP1 also regulates angiogenesis, the effect of PARP-1 proteolysis by MMPs during angiogenesis may be important to investigate for cancer and chronic inflammation therapy.

\section{Conclusions}

The molecular mechanisms involved in balancing life and death decisions controlled by PARP-1 are highly complex and incompletely understood. A delicate PARP-1 equilibrium exists within cells where any deviation, either hyper- or hypo-activity can induce or exacerbate pathology. Many related proteases including caspases, calpains, cathepsins, granzymes and MMPs also directly and indirectly mediate the effects of PARP-1 in these phenomena. Recent reports indicate that PARP-1 contributions to cell death are insult- and context-dependent. PARP-1 can also promote tissue survival by shifting the balance of cell death programs between autophagy and necrosis. PARP-1's role in driving autophagy from necrosis is distinctive from its classical role and highlights its importance in cell survival decisions. It also points out an important potential application through which modulation of PARP-1 may be applied therapeutically. Because of PARP-1's dual nature in life: death control, PARP inhibitors should be used with great caution. Furthermore, physiological and pathological roles of poly (ADP-ribosyl)ation in parthanatos and long term memory suggest that prolonged inhibition of PARP-1 may be ultimately deleterious. Conversely, the $24-\mathrm{kD} \mathrm{N}$ terminal PARP-1 apoptotic fragment that attenuates necrotic cell death might eventually be developed for therapy. The appearance of specific PARP-1 fragments will not only help us understand the involvement of specific cell death proteases in particular processes, but also different types of cell death. These recent findings clearly indicate that a great deal remains be defined about PARP-1, the roles of its fragments and the specific molecular mechanisms they regulate during various forms of cell death.

\section{Additional material}

Additional file 1: Table -1. PARP-1 signature fragments. Action of various proteases results in the generation of PARP-1 fragments with specific molecular weights that can be correlated with the action of specific proteases. PARP-1 signature fragments generated by various proteases are listed above.

\section{Acknowledgements}

The authors are grateful for the excellent editorial help of Ms. Merilyn Jennings, Department of Molecular and Cellular Physiology, LSUHSCShreveport, LA in the preparation of this review. The authors thank Prof. K. 
Subba Rao, INSA Senior Scientist, JNTU, Hyderabad, India for critical suggestions. Post-doctoral fellowship from the Malcolm Feist Cardiovascular Research Endowment- LSU Health Sciences Center-Shreveport to Ganta Vijay Chaitanya is acknowledged. Funding from DBT, DST and ICMR, New Delhi, Government of India to Prof. Prakash Babu is acknowledged.

\section{Author details}

'Department of Biotechnology, School of Life Sciences, University of Hyderabad, Hyderabad, India. ${ }^{2}$ Department of Molecular and Cellular Physiology, Louisiana State University Health Sciences Center-Shreveport, Louisiana-USA.

\section{Authors' contributions}

GVC wrote and edited the manuscript, JSA edited the manuscript and PPB edited and communicated the manuscript. All authors read and approved the final manuscript.

\section{Competing interests}

The authors declare that they have no competing interests.

Received: 16 July 2010 Accepted: 22 December 2010

Published: 22 December 2010

\section{References}

1. Dantzer F, de La RG, Menissier-de Murcia J, Hostomsky Z, de Murcia G, Schreiber V: Base excision repair is impaired in mammalian cells lacking Poly(ADP-ribose) polymerase-1. Biochemistry 2000, 39:7559-7569.

2. Dantzer F, Schreiber V, Niedergang C, Trucco C, Flatter E, de La RG, et al: Involvement of poly(ADP-ribose) polymerase in base excision repair. Biochimie 1999, 81:69-75.

3. Audebert M, Salles B, Calsou P: Involvement of poly(ADP-ribose) polymerase-1 and XRCC1/DNA ligase III in an alternative route for DNA double-strand breaks rejoining. J Biol Chem 2004 279:55117-55126.

4. Benjamin RC, Gill DM: Poly(ADP-ribose) synthesis in vitro programmed by damaged DNA. A comparison of DNA molecules containing different types of strand breaks. J Biol Chem 1980, 255:10502-10508

5. Fisher $A E$, Hochegger $H$, Takeda $S$, Caldecott KW: Poly(ADP-ribose) polymerase 1 accelerates single-strand break repair in concert with poly (ADP-ribose) glycohydrolase. Mol Cell Biol 2007, 27:5597-5605.

6. Wang $M$, Wu W, Wu W, Rosidi B, Zhang L, Wang H, et al: PARP-1 and Ku compete for repair of DNA double strand breaks by distinct NHEJ pathways. Nucleic Acids Res 2006, 34:6170-6182.

7. Susse S, Scholz CJ, Burkle A, Wiesmuller L: Poly(ADP-ribose) polymerase (PARP-1) and p53 independently function in regulating double-strand break repair in primate cells. Nucleic Acids Res 2004, 32:669-680.

8. Koh DW, Dawson TM, Dawson VL: Poly(ADP-ribosyl)ation regulation of life and death in the nervous system. Cellular and Molecular Life Sciences 2005 62:760-768.

9. Albadawi $\mathrm{H}$, Crawford RS, Atkins MD, Watkins MT: Role of poly(ADP-ribose) polymerase during vascular reconstruction. Vascular 2006, 14:362-365.

10. Burkle A, Brabeck C, Diefenbach J, Beneke S: The emerging role of poly (ADP-ribose) polymerase-1 in longevity. Int J Biochem Cell Biol 2005, 37:1043-1053.

11. Chiarugi A, Moskowitz MA: Poly(ADP-ribose) polymerase-1 activity promotes NF-kappaB-driven transcription and microglial activation: implication for neurodegenerative disorders. J Neurochem 2003, 85:306-317.

12. Hernandez Al, Wolk J, Hu JY, Liu J, Kurosu T, Schwartz JH, et al: Poly-(ADPribose) polymerase- 1 is necessary for long-term facilitation in Aplysia. $J$ Neurosci 2009, 29:9553-9562.

13. Kraus WL, Lis JT: PARP goes transcription. Cell 2003, 113:677-683.

14. Phulwani NK, Kielian T: Poly (ADP-ribose) polymerases (PARPs) 1-3 regulate astrocyte activation. J Neurochem 2008, 106:578-590.

15. Sung YJ, Ambron RT: PolyADP-ribose polymerase-1 (PARP-1) and the evolution of learning and memory. Bioessays 2004, 26:1268-1271.

16. von Lukowicz T, Hassa PO, Lohmann C, Boren J, Braunersreuther V, Mach F, et al: PARP1 is required for adhesion molecule expression in atherogenesis. Cardiovasc Res 2008, 78:158-166.

17. Xiao CY, Chen M, Zsengeller Z, Li H, Kiss L, Kollai M, et al: Poly(ADP-Ribose) polymerase promotes cardiac remodeling, contractile failure, and translocation of apoptosis-inducing factor in a murine experimental model of aortic banding and heart failure. J Pharmacol Exp Ther 2005, 312:891-898.

18. Aguennouz M, Vita GL, Messina S, Cama A, Lanzano N, Ciranni A, et al: Telomere shortening is associated to TRF1 and PARP1 overexpression in Duchenne muscular dystrophy. Neurobiol Aging 2010.

19. Wang ZQ, Auer B, Stingl L, Berghammer $H$, Haidacher $D$, Schweiger $M$, et al: Mice lacking ADPRT and poly(ADP-ribosyl)ation develop normally but are susceptible to skin disease. Genes Dev 1995, 9:509-520

20. Simbulan-Rosenthal CM, Ly DH, Rosenthal DS, Konopka G, Luo R, Wang ZQ, et al: Misregulation of gene expression in primary fibroblasts lacking poly(ADP-ribose) polymerase. Proc Natl Acad Sci USA 2000, 97:11274-11279.

21. Ogino H, Nozaki T, Gunji A, Maeda M, Suzuki H, Ohta T, et al: Loss of Parp1 affects gene expression profile in a genome-wide manner in ES cells and liver cells. BMC Genomics 2007, 8:41.

22. Zingarelli B, Hake PW, O'Connor M, Denenberg A, Kong S, Aronow BJ: Absence of poly(ADP-ribose)polymerase-1 alters nuclear factor-kappa B activation and gene expression of apoptosis regulators after reperfusion injury. Mol Med 2003, 9:143-153.

23. Simbulan-Rosenthal CM, Rosenthal DS, Luo R, Samara R, Espinoza LA, Hassa PO, et al: PARP-1 binds E2F-1 independently of its DNA binding and catalytic domains, and acts as a novel coactivator of E2F-1mediated transcription during re-entry of quiescent cells into $S$ phase. Oncogene 2003, 22:8460-8471

24. Olabisi OA, Soto-Nieves N, Nieves E, Yang TT, Yang X, Yu RY, et al: Regulation of transcription factor NFAT by ADP-ribosylation. Mol Cell Biol 2008, 28:2860-2871.

25. Hassa PO, Hottiger MO: A role of poly (ADP-ribose) polymerase in NFkappaB transcriptional activation. Biol Chem 1999, 380:953-959.

26. Hassa PO, Hottiger MO: The functional role of poly(ADP-ribose) polymerase 1 as novel coactivator of NF-kappaB in inflammatory disorders. Cell Mol Life Sci 2002, 59:1534-1553.

27. Cohen-Armon M, Visochek L, Rozensal D, Kalal A, Geistrikh I, Klein R, et al: DNA-independent PARP-1 activation by phosphorylated ERK2 increases Elk1 activity: a link to histone acetylation. Mol Cell 2007, 25:297-308.

28. Cohen-Armon M: PARP-1 activation in the ERK signaling pathway. Trends Pharmacol Sci 2007, 28:556-560

29. Oshima T, Pavlick KP, Laroux FS, Verma SK, Jordan P, Grisham MB, et al: Regulation and distribution of MAdCAM-1 in endothelial cells in vitro. Am J Physiol Cell Physiol 2001, 281:C1096-C1105.

30. Sharp C, Warren A, Oshima T, Williams L, Li JH, Alexander JS: Poly ADP ribose-polymerase inhibitors prevent the upregulation of ICAM-1 and Eselectin in response to Th1 cytokine stimulation. Inflammation 2001, 25:157-163.

31. Ame JC, Spenlehauer C, de Murcia G: The PARP superfamily. Bioessays 2004, 26:882-893.

32. Yamanaka $H$, Penning CA, Willis EH, Wasson DB, Carson DA Characterization of human poly(ADP-ribose) polymerase with autoantibodies. J Biol Chem 1988, 263:3879-3883.

33. Woodhouse BC, Dianov GL: Poly ADP-ribose polymerase-1: an international molecule of mystery. DNA Repair (Amst) 2008, 7:1077-1086.

34. D'Amours D, Desnoyers S, D'Silva I, Poirier GG: Poly(ADP-ribosyl)ation reactions in the regulation of nuclear functions. Biochem J 1999, 342(Pt 2):249-268.

35. Scovassi Al: The poly(ADP-ribosylation) story: a long route from Cinderella to Princess. Riv Biol 2007, 100:351-360.

36. Althaus FR, Richter C: ADP-ribosylation of proteins. Enzymology and biological significance. Mol Biol Biochem Biophys 1987, 37:1-237.

37. Choudhary C, Kumar C, Gnad F, Nielsen ML, Rehman M, Walther TC, et al: Lysine acetylation targets protein complexes and co-regulates major cellular functions. Science 2009, 325:834-840.

38. Perrot $R$, Berges $R$, Bocquet $A$, Eyer J: Review of the multiple aspects of neurofilament functions, and their possible contribution to neurodegeneration. Mol Neurobiol 2008, 38:27-65.

39. Shukla A, Chaurasia P, Bhaumik SR: Histone methylation and ubiquitination with their cross-talk and roles in gene expression and stability. Cell Mol Life Sci 2009, 66:1419-1433.

40. Rolli V, O'Farrell M, Menissier-de Murcia J, de Murcia G: Random mutagenesis of the poly(ADP-ribose) polymerase catalytic domain reveals amino acids involved in polymer branching. Biochemistry 1997 36:12147-12154. 
41. Chang P, Jacobson MK, Mitchison TJ: Poly(ADP-ribose) is required for spindle assembly and structure. Nature 2004, 432:645-649.

42. Herceg Z, Wang ZQ: Functions of poly(ADP-ribose) polymerase (PARP) in DNA repair, genomic integrity and cell death. Mutat Res 2001, 477:97-110.

43. Ullrich O, Diestel A, Bechmann I, Homberg M, Grune T, Hass R, et al: Turnover of oxidatively damaged nuclear proteins in BV-2 microglial cells is linked to their activation state by poly-ADP-ribose polymerase. FASEB J 2001, 15:1460-1462

44. Kun E, Kirsten E, Mendeleyev J, Ordahl CP: Regulation of the enzymatic catalysis of poly(ADP-ribose) polymerase by dsDNA, polyamines, Mg2+, Ca2+, histones H1 and H3, and ATP. Biochemistry 2004, 43:210-216.

45. Potaman VN, Shlyakhtenko LS, Oussatcheva EA, Lyubchenko YL, Soldatenkov VA: Specific binding of poly(ADP-ribose) polymerase-1 to cruciform hairpins. J Mol Biol 2005, 348:609-615.

46. Wacker DA, Ruhl DD, Balagamwala EH, Hope KM, Zhang T, Kraus WL: The DNA binding and catalytic domains of poly(ADP-ribose) polymerase 1 cooperate in the regulation of chromatin structure and transcription. Mol Cell Biol 2007, 27:7475-7485.

47. Langelier MF, Servent KM, Rogers EE, Pascal JM: A third zinc-binding domain of human poly(ADP-ribose) polymerase-1 coordinates DNAdependent enzyme activation. J Biol Chem 2008, 283:4105-4114

48. El Khamisy SF, Masutani M, Suzuki H, Caldecott KW: A requirement for PARP-1 for the assembly or stability of XRCC1 nuclear foci at sites of oxidative DNA damage. Nucleic Acids Res 2003, 31:5526-5533.

49. Masson M, Niedergang C, Schreiber V, Muller S, Menissier-de Murcia J, de Murcia G: XRCC1 is specifically associated with poly(ADP-ribose) polymerase and negatively regulates its activity following DNA damage. Mol Cell Biol 1998, 18:3563-3571.

50. Galluzzi L, Joza N, Tasdemir E, Maiuri MC, Hengartner M, Abrams JM, et al: No death without life: vital functions of apoptotic effectors. Cell Death Differ 2008, 15:1113-1123.

51. Oberst A, Bender C, Green DR: Living with death: the evolution of the mitochondrial pathway of apoptosis in animals. Cell Death Differ 2008, 15:1139-1146.

52. Cotter TG: Apoptosis and cancer: the genesis of a research field. Nat Rev Cancer 2009, 9:501-507.

53. Yakovlev AG, Faden Al: Caspase-dependent apoptotic pathways in CNS injury. Mol Neurobiol 2001, 24:131-144.

54. Li J, Yuan J: Caspases in apoptosis and beyond. Oncogene 2008, 27:6194-6206.

55. Fan Y, Bergmann A: Apoptosis-induced compensatory proliferation. The Cell is dead. Long live the Cell! Trends Cell Biol 2008, 18:467-473.

56. Fan $Y$, Bergmann A: Distinct mechanisms of apoptosis-induced compensatory proliferation in proliferating and differentiating tissues in the Drosophila eye. Dev Cell 2008, 14:399-410.

57. Wells BS, Yoshida E, Johnston LA: Compensatory proliferation in Drosophila imaginal discs requires Dronc-dependent p53 activity. Curr Biol 2006, 16:1606-1615.

58. Kondo S, Senoo-Matsuda N, Hiromi Y, Miura M: DRONC coordinates cell death and compensatory proliferation. Mol Cell Biol 2006, 26:7258-7268.

59. Droin N, Jacquel A, Guery L, Dufour E, Garrido C, Solary E: Various functions of caspases in hematopoiesis. Front Biosci 2009, 14:2358-2371.

60. Gulyaeva NV: Non-apoptotic functions of caspase-3 in nervous tissue. Biochemistry (Mosc) 2003, 68:1171-1180.

61. Gulyaeva NV, Kudryashov IE, Kudryashova IV: Caspase activity is essential for long-term potentiation. J Neurosci Res 2003, 73:853-864.

62. Fischer U, Janicke RU, Schulze-Osthoff K: Many cuts to ruin: a comprehensive update of caspase substrates. Cell Death Differ 2003, 10:76-100.

63. Kaufmann SH, Desnoyers S, Ottaviano Y, Davidson NE, Poirier GG: Specific proteolytic cleavage of poly(ADP-ribose) polymerase: an early marker of chemotherapy-induced apoptosis. Cancer Res 1993, 53:3976-3985.

64. Tewari M, Quan LT, O'Rourke K, Desnoyers S, Zeng Z, Beidler DR, et al: Yama/CPP32 beta, a mammalian homolog of CED-3, is a CrmAinhibitable protease that cleaves the death substrate poly(ADP-ribose) polymerase. Cell 1995, 81:801-809.

65. Margolin N, Raybuck SA, Wilson KP, Chen W, Fox T, Gu Y, et al: Substrate and inhibitor specificity of interleukin-1 beta-converting enzyme and related caspases. J Biol Chem 1997, 272:7223-7228.

66. Lazebnik YA, Kaufmann SH, Desnoyers S, Poirier GG, Earnshaw WC: Cleavage of poly(ADP-ribose) polymerase by a proteinase with properties like ICE. Nature 1994, 371:346-347.
67. Bhaskara VK, Panigrahi M, Challa S, Babu PP: Comparative status of activated ERK1/2 and PARP cleavage in human gliomas. Neuropathology 2005, 25:48-53.

68. Bhaskara VK, Challa S, Panigrahi M, Babu PP: Differential PARP cleavage: An indication for existence of multiple forms of cell death in human gliomas. Neurol India 2009, 57:264-268.

69. Chaitanya GV, Babu PP: Activation of calpain, cathepsin-b and caspase-3 during transient focal cerebral ischemia in rat model. Neurochem Res 2008, 33:2178-2186.

70. Chaitanya GV, Babu PP: Differential PARP cleavage: an indication of heterogeneous forms of cell death and involvement of multiple proteases in the infarct of focal cerebral ischemia in rat. Cell Mol Neurobiol 2009, 29:563-573.

71. Gilliams-Francis KL, Quaye AA, Naegele JR: PARP cleavage, DNA fragmentation, and pyknosis during excitotoxin-induced neuronal death. Exp Neurol 2003, 184:359-372

72. Kanthasamy AG, Anantharam $V$, Zhang D, Latchoumycandane $C$, Jin $H$ Kaul S, et al: A novel peptide inhibitor targeted to caspase-3 cleavage site of a proapoptotic kinase protein kinase $C$ delta (PKCdelta) protects against dopaminergic neuronal degeneration in Parkinson's disease models. Free Radic Biol Med 2006, 41:1578-1589.

73. Lau A, Arundine M, Sun HS, Jones M, Tymianski M: Inhibition of caspasemediated apoptosis by peroxynitrite in traumatic brain injury. I Neurosci 2006, 26:11540-11553.

74. Peng QL, Buz'Zard AR, Lau BH: Pycnogenol protects neurons from amyloidbeta peptide-induced apoptosis. Brain Res Mol Brain Res 2002, 104:55-65.

75. Soldani C, Lazze MC, Bottone MG, Tognon G, Biggiogera M, Pellicciari CE, et al: Poly(ADP-ribose) polymerase cleavage during apoptosis: when and where? Exp Cell Res 2001, 269:193-201.

76. D'Amours D, Sallmann FR, Dixit VM, Poirier GG: Gain-of-function of poly (ADP-ribose) polymerase-1 upon cleavage by apoptotic proteases: implications for apoptosis. J Cell Sci 2001, 114:3771-3778.

77. Smulson ME, Pang D, Jung M, Dimtchev A, Chasovskikh S, Spoonde A, et al: Irreversible binding of poly(ADP)ribose polymerase cleavage product to DNA ends revealed by atomic force microscopy: possible role in apoptosis. Cancer Res 1998, 58:3495-3498.

78. Alvarez-Gonzalez R, Spring H, Muller M, Burkle A: Selective loss of poly (ADP-ribose) and the 85-kDa fragment of poly(ADP-ribose) polymerase in nucleoli during alkylation-induced apoptosis of HeLa cells. J Biol Chem 1999, 274:32122-32126.

79. Germain M, Affar EB, D'Amours D, Dixit VM, Salvesen GS, Poirier GG: Cleavage of automodified poly(ADP-ribose) polymerase during apoptosis. Evidence for involvement of caspase-7. J Biol Chem 1999, 274:28379-28384.

80. Eguchi Y, Shimizu S, Tsujimoto Y: Intracellular ATP levels determine cell death fate by apoptosis or necrosis. Cancer Res 1997, 57:1835-1840.

81. Lemaire C, Andreau K, Souvannavong V, Adam A: Inhibition of caspase activity induces a switch from apoptosis to necrosis. FEBS Lett 1998, 425:266-270.

82. Herceg Z, Wang ZQ: Failure of poly(ADP-ribose) polymerase cleavage by caspases leads to induction of necrosis and enhanced apoptosis. Mol Cell Biol 1999, 19:5124-5133.

83. Aikin R, Rosenberg L, Paraskevas S, Maysinger D: Inhibition of caspasemediated PARP-1 cleavage results in increased necrosis in isolated islets of Langerhans. J Mol Med 2004, 82:389-397.

84. Los M, Mozoluk M, Ferrari D, Stepczynska A, Stroh C, Renz A, et al: Activation and caspase-mediated inhibition of PARP: a molecular switch between fibroblast necrosis and apoptosis in death receptor signaling. Mol Biol Cell 2002, 13:978-988.

85. Huang Y, Wang KK: The calpain family and human disease. Trends Mol Med 2001, 7:355-362

86. Verkhratsky A: Calcium and cell death. Subcell Biochem 2007, 45:465-480.

87. Bhupanapadu S, Swain U, Babu PP: Cell death is associated with reduced base excision repair during chronic alcohol administration in adult rat brain. Neurochem Res 2008, 33:1117-1128.

88. Bizat N, Hermel JM, Boyer F, Jacquard C, Creminon C, Ouary S, et al: Calpain is a major cell death effector in selective striatal degeneration induced in vivo by 3-nitropropionate: implications for Huntington's disease. J Neurosci 2003, 23:5020-5030.

89. Goni-Oliver P, Avila J, Hernandez F: Memantine Inhibits Calpain-Mediated Truncation of GSK-3 Induced by NMDA: Implications in Alzheimer's Disease. J Alzheimers Dis 2009, 18:843-848. 
90. Samantaray S, Ray SK, Banik NL: Calpain as a potential therapeutic target in Parkinson's disease. CNS Neurol Disord Drug Targets 2008, 7:305-312.

91. Shukla M, Rajgopal Y, Babu PP: Activation of calpains, calpastatin and spectrin cleavage in the brain during the pathology of fatal murine cerebral malaria. Neurochem Int 2006, 48:108-113.

92. Zhou M, Xu W, Liao G, Bi X, Baudry M: Neuroprotection against neonatal hypoxia/ischemia-induced cerebral cell death by prevention of calpainmediated mGluR1alpha truncation. Exp Neurol 2009, 218:75-82.

93. Michetti M, Salamino F, Tedesco I, Averna M, Minafra R, Melloni E, et al: Autolysis of human erythrocyte calpain produces two active enzyme forms with different cell localization. FEBS Lett 1996, 392:11-15.

94. Hewitt KE, Lesiuk HJ, Tauskela JS, Morley P, Durkin JP: Selective coupling of mu-calpain activation with the NMDA receptor is independent of translocation and autolysis in primary cortical neurons. J Neurosci Res 1998, 54:223-232.

95. Dutt $\mathrm{P}$, Croall DE, Arthur JS, Veyra TD, Williams K, Elce JS, et al: $\mathrm{m}$-Calpain is required for preimplantation embryonic development in mice. BMC Dev Biol 2006, 6:3.

96. Liang YC, Yeh JY, Forsberg NE, Ou BR: Involvement of mu- and m-calpains and protein kinase $\mathrm{C}$ isoforms in $\mathrm{L} 8$ myoblast differentiation. Int J Biochem Cell Biol 2006, 38:662-670.

97. Wu HY, Lynch DR: Calpain and synaptic function. Mol Neurobiol 2006, 33:215-236.

98. Franco SJ, Huttenlocher A: Regulating cell migration: calpains make the cut. J Cell Sci 2005, 118:3829-3838.

99. Ma H, Tochigi A, Shearer TR, Azuma M: Calpain inhibitor SNJ-1945 attenuates events prior to angiogenesis in cultured human retinal endothelial cells. J Ocul Pharmacol Ther 2009, 25:409-414.

100. Su Y, Cui Z, Li Z, Block ER: Calpain-2 regulation of VEGF-mediated angiogenesis. FASEB J 2006, 20:1443-1451

101. Rajesh M, Mukhopadhyay P, Batkai S, Godlewski G, Hasko G, Liaudet L, et al: Pharmacological inhibition of poly(ADP-ribose) polymerase inhibits angiogenesis. Biochem Biophys Res Commun 2006, 350:352-357.

102. Virag L, Scott GS, Antal-Szalmas P, O'Connor M, Ohshima H, Szabo C: Requirement of intracellular calcium mobilization for peroxynitriteinduced poly(ADP-ribose) synthetase activation and cytotoxicity. $\mathrm{Mol}$ Pharmacol 1999, 56:824-833.

103. Bentle MS, Reinicke KE, Bey EA, Spitz DR, Boothman DA: Calciumdependent modulation of poly(ADP-ribose) polymerase-1 alters cellular metabolism and DNA repair. J Biol Chem 2006, 281:33684-33696.

104. Szenczi $O$, Kemecsei $P$, Holthuijsen MF, van Riel NA, van der Vusse GJ, Pacher $P$, et al: Poly(ADP-ribose) polymerase regulates myocardial calcium handling in doxorubicin-induced heart failure. Biochem Pharmacol 2005, 69:725-732.

105. Duan Y, Gross RA, Sheu SS: Ca2+-dependent generation of mitochondrial reactive oxygen species serves as a signal for poly(ADP-ribose) polymerase1 activation during glutamate excitotoxicity. J Physiol 2007, 585:741-758.

106. Vosler PS, Sun D, Wang S, Gao Y, Kintner DB, Signore AP, et al: Calcium dysregulation induces apoptosis-inducing factor release: Cross-talk between PARP-1- and calpain- signaling pathways. Exp Neurol 2009, 218:213-220

107. Liu L, Xing D, Chen WR: mu-Calpain regulates caspase-dependent and apoptosis inducing factor-mediated caspase-independent apoptotic pathways in cisplatin-induced apoptosis. Int J Cancer 2009, 15;125(12):2757-66.

108. Liu X, Van Vleet T, Schnellmann RG: The role of calpain in oncotic cell death. Annu Rev Pharmacol Toxicol 2004, 44:349-370.

109. Melloni E, Michetti M, Salamino F, Minafra R, Pontremoli S: Modulation of the calpain autoproteolysis by calpastatin and phospholipids. Biochem Biophys Res Commun 1996, 229:193-197.

110. Melloni E, Averna M, Salamino F, Sparatore B, Minafra R, Pontremoli S: AcylCoA-binding protein is a potent m-calpain activator. J Biol Chem 2000, 275:82-86.

111. Suzuki K, Sorimachi H: A novel aspect of calpain activation. FEBS Lett 1998, 433:1-4.

112. Neumar RW, Xu YA, Gada H, Guttmann RP, Siman R: Cross-talk between calpain and caspase proteolytic systems during neuronal apoptosis. $J$ Biol Chem 2003, 278:14162-14167.

113. Wang KK: Calpain and caspase: can you tell the difference? Trends Neurosci 2000, 23:20-26.
114. McGinnis KM, Gnegy ME, Park YH, Mukerjee N, Wang KK: Procaspase-3 and poly(ADP)ribose polymerase (PARP) are calpain substrates. Biochem Biophys Res Commun 1999, 263:94-99.

115. Buki KG, Bauer PI, Kun E: Isolation and identification of a proteinase from calf thymus that cleaves poly(ADP-ribose) polymerase and histone $\mathrm{H} 1$. Biochim Biophys Acta 1997, 1338:100-106.

116. Gafni J, Cong X, Chen SF, Gibson BW, Ellerby LM: Calpain-1 cleaves and activates caspase-7. J Biol Chem 2009, 284:25441-25449.

117. Saftig P, Klumperman J: Lysosome biogenesis and lysosomal membrane proteins: trafficking meets function. Nat Rev Mol Cell Biol 2009, 10:623-635.

118. Artal-Sanz M, Samara C, Syntichaki P, Tavernarakis N: Lysosomal biogenesis and function is critical for necrotic cell death in Caenorhabditis elegans. J Cell Biol 2006, 173:231-239.

119. Ivanova S, Repnik U, Bojic L, Petelin A, Turk V, Turk B: Lysosomes in apoptosis. Methods Enzymol 2006, 442:183-199.

120. Pacheco FJ, Servin J, Dang D, Kim J, Molinaro C, Daniels T, et al: Involvement of lysosomal cathepsins in the cleavage of DNA topoisomerase I during necrotic cell death. Arthritis Rheum 2005, 52:2133-2145.

121. He C, Klionsky DJ: Regulation Mechanisms and Signaling Pathways of Autophagy. Annu Rev Genet 2009, 43:67-93.

122. Wen YD, Sheng $R$, Zhang LS, Han R, Zhang $X$, Zhang XD, et al: Neuronal injury in rat model of permanent focal cerebral ischemia is associated with activation of autophagic and lysosomal pathways. Autophagy 2008 , 4:762-769.

123. Saelens X, Festjens N, Parthoens E, Vanoverberghe I, Kalai M, van Kuppeveld $F$, et al: Protein synthesis persists during necrotic cell death. J Cell Biol 2005, 168:545-551.

124. Wilson TJ, Nannuru KC, Futakuchi M, Singh RK: Cathepsin G-mediated enhanced TGF-beta signaling promotes angiogenesis via upregulation of VEGF and MCP-1. Cancer Lett 2009, 28;288(2):162-9.

125. Burden RE, Gormley JA, Jaquin TJ, Small DM, Quinn DJ, Hegarty SM, et al: Antibody-mediated inhibition of cathepsin S blocks colorectal tumor invasion and angiogenesis. Clin Cancer Res 2009, 15:6042-6051.

126. Yang Y, Zhao S, Song J: Caspase-dependent apoptosis and -independent poly(ADP-ribose) polymerase cleavage induced by transforming growth factor beta1. Int J Biochem Cell Biol 2004, 36:223-234

127. Gobeil S, Boucher CC, Nadeau D, Poirier GG: Characterization of the necrotic cleavage of poly(ADP-ribose) polymerase (PARP-1): implication of lysosomal proteases. Cell Death Differ 2001, 8:588-594.

128. Chavez-Galan L, Arenas-Del Angel MC, Zenteno E, Chavez R, Lascurain R Cell death mechanisms induced by cytotoxic lymphocytes. Cell Mol Immunol 2009, 6:15-25.

129. Trapani JA: Granzymes: a family of lymphocyte granule serine proteases. Genome Biol 2001, 2:REVIEWS3014.

130. Romero V, Andrade F: Non-apoptotic functions of granzymes. Tissue Antigens 2008, 71:409-416.

131. Choy JC, Cruz RP, Kerjner A, Geisbrecht J, Sawchuk T, Fraser SA, et al: Granzyme B induces endothelial cell apoptosis and contributes to the development of transplant vascular disease. Am J Transplant 2005, 5:494-499.

132. Choy JC, McDonald PC, Suarez AC, Hung VH, Wilson JE, MCManus BM, et al: Granzyme $B$ in atherosclerosis and transplant vascular disease: association with cell death and atherosclerotic disease severity. Mod Pathol 2003, 16:460-470.

133. Blanco P, Pitard V, Viallard JF, Taupin JL, Pellegrin JL, Moreau JF: Increase in activated CD8+ T lymphocytes expressing perforin and granzyme B correlates with disease activity in patients with systemic lupus erythematosus. Arthritis Rheum 2005, 52:201-211.

134. Saito S, Murakoshi K, Kotake S, Kamatani N, Tomatsu T: Granzyme B induces apoptosis of chondrocytes with natural killer cell-like cytotoxicity in rheumatoid arthritis. J Rheumatol 2008, 35:1932-1943.

135. Tschopp CM, Spiegl N, Didichenko S, Lutmann W, Julius P, Virchow JC, et al: Granzyme B, a novel mediator of allergic inflammation: its induction and release in blood basophils and human asthma. Blood 2006 108:2290-2299.

136. Humbert M, Magnan A, Ladurie FL, Dartevelle P, Simonneau G, Duroux $P$, et al: Perforin and granzyme B gene-expressing cells in bronchoalveolar lavage fluids from lung allograft recipients displaying cytomegalovirus pneumonitis. Transplantation 1994, 57:1289-1292. 
137. Chaitanya GV, Kolli M, Babu PP: Granzyme-b mediated cell death in the spinal cord-injured rat model. Neuropathology 2009, 29:270-279.

138. Wang T, Allie R, Conant K, Haughey N, Turchan-Chelowo J, Hahn K, et al: Granzyme B mediates neurotoxicity through a G-protein-coupled receptor. FASEB J 2006, 20:1209-1211.

139. Chaitanya GV, Schwaninger M, Alexander JS, Babu PP: Granzyme-b is involved in mediating post-ischemic neuronal death during focal cerebral ischemia in rat model. Neuroscience 2010, 165:1203-1216.

140. Trapani JA, Sutton VR: Granzyme B: pro-apoptotic, antiviral and antitumor functions. Curr Opin Immunol 2003, 15:533-543.

141. Martinvalet D, Thiery J: [A novel caspase-independent apoptotic pathway triggered by Granzyme A]. Med Sci (Paris) 2008, 24:901-903.

142. Martinvalet D, Dykxhoorn DM, Ferrini R, Lieberman J: Granzyme A cleaves a mitochondrial complex I protein to initiate caspase-independent cell death. Cell 2008, 133:681-692.

143. Zhu P, Zhang D, Chowdhury D, Martinvalet D, Keefe D, Shi L, et al: Granzyme A, which causes single-stranded DNA damage, targets the double-strand break repair protein Ku70. EMBO Rep 2006, 7:431-437.

144. Beresford PJ, Zhang D, Oh DY, Fan Z, Greer EL, Russo ML, et al: Granzyme A activates an endoplasmic reticulum-associated caspase-independent nuclease to induce single-stranded DNA nicks. J Biol Chem 2001, 276:43285-43293.

145. Zhu P, Martinvalet D, Chowdhury D, Zhang D, Schlesinger A, Lieberman J: The cytotoxic T lymphocyte protease granzyme $A$ cleaves and inactivates poly(adenosine 5'-diphosphate-ribose) polymerase-1. Blood 2009, 114:1205-1216.

146. Zhang D, Beresford PJ, Greenberg AH, Lieberman J: Granzymes A and B directly cleave lamins and disrupt the nuclear lamina during granulemediated cytolysis. Proc Natl Acad Sci USA 2001, 98:5746-5751.

147. Froelich CJ, Hanna WL, Poirier GG, Duriez PJ, D'Amours D, Salvesen GS, et al: Granzyme B/perforin-mediated apoptosis of Jurkat cells results in cleavage of poly(ADP-ribose) polymerase to the 89-kDa apoptotic fragment and less abundant 64-kDa fragment. Biochem Biophys Res Commun 1996, 227:658-665.

148. Waterhouse NJ, Sedelies KA, Trapani JA: Role of Bid-induced mitochondrial outer membrane permeabilization in granzyme B-induced apoptosis. Immunol Cell Biol 2006, 84:72-78.

149. Adrain C, Murphy BM, Martin SJ: Molecular ordering of the caspase activation cascade initiated by the cytotoxic $\mathrm{T}$ lymphocyte/natural killer (CTL/NK) protease granzyme B. J Biol Chem 2005, 280:4663-4673.

150. Krishnamurthy P, Peterson JT, Subramanian V, Singh M, Singh K: Inhibition of matrix metalloproteinases improves left ventricular function in mice lacking osteopontin after myocardial infarction. Mol Cell Biochem 2009, 322:53-62.

151. Candelario-Jalil E, Yang Y, Rosenberg GA: Diverse roles of matrix metalloproteinases and tissue inhibitors of metalloproteinases in neuroinflammation and cerebral ischemia. Neuroscience 2009 158:983-994

152. Lehrke M, Greif M, Broedl UC, Lebherz C, Laubender RP, Becker A, et al: MMP-1 serum levels predict coronary atherosclerosis in humans. Cardiovasc Diabetol 2009, 8:50.

153. Kwan JA, Schulze CJ, Wang W, Leon $H$, Sariahmetoglu $M$, Sung $M$, et al: Matrix metalloproteinase-2 (MMP-2) is present in the nucleus of cardiac myocytes and is capable of cleaving poly (ADP-ribose) polymerase (PARP) in vitro. FASEB J 2004, 18:690-692.

154. Raffetto JD, Khalil RA: Matrix metalloproteinases and their inhibitors in vascular remodeling and vascular disease. Biochem Pharmacol 2008, 75:346-359.

155. Dean RA, Butler GS, Hamma-Kourbali Y, Delbe J, Brigstock DR, Courty J, et al: Identification of candidate angiogenic inhibitors processed by matrix metalloproteinase 2 (MMP-2) in cell-based proteomic screens: disruption of vascular endothelial growth factor (VEGF)/heparin affin regulatory peptide (pleiotrophin) and VEGF/Connective tissue growth factor angiogenic inhibitory complexes by MMP-2 proteolysis. Mol Cell Biol 2007, 27:8454-8465.

156. Tang J, Liu J, Zhou C, Alexander JS, Nanda A, Granger DN, et al: Mmp-9 deficiency enhances collagenase-induced intracerebral hemorrhage and brain injury in mutant mice. J Cereb Blood Flow Metab 2004, 24:1133-1145.

157. Wang L, Zhang ZG, Zhang RL, Gregg SR, Hozeska-Solgot A, LeTourneau Y, et al: Matrix metalloproteinase 2 (MMP2) and MMP9 secreted by erythropoietin-activated endothelial cells promote neural progenitor cell migration. J Neurosci 2006, 26:5996-6003.

158. Mandler RN, Dencoff JD, Midani F, Ford CC, Ahmed W, Rosenberg GA: Matrix metalloproteinases and tissue inhibitors of metalloproteinases in cerebrospinal fluid differ in multiple sclerosis and Devic's neuromyelitis optica. Brain 2001, 124:493-498.

159. Nicolescu AC, Holt A, Kandasamy AD, Pacher P, Schulz R: Inhibition of matrix metalloproteinase- 2 by PARP inhibitors. Biochem Biophys Res Commun 2009, 387:646-650.

doi:10.1186/1478-811X-8-31

Cite this article as: Chaitanya et al:: PARP-1 cleavage fragments: signatures of cell-death proteases in neurodegeneration. Cell Communication and Signaling 2010 8:31.

\section{Submit your next manuscript to BioMed Central and take full advantage of:}

- Convenient online submission

- Thorough peer review

- No space constraints or color figure charges

- Immediate publication on acceptance

- Inclusion in PubMed, CAS, Scopus and Google Scholar

- Research which is freely available for redistribution

Submit your manuscript at www.biomedcentral.com/submit
C Biomed Central 